\title{
Extra low interstitial titanium based fully porous morphological bone scaffolds manufactured using selective laser melting
}

\author{
Klaudio Bari ${ }^{{ }^{*}}$ and Arun Arjunan ${ }^{a}$ \\ a School of Engineering, Faculty of Science and Engineering, University of Wolverhampton, \\ Telford Campus, Telford, TF2 9NT, United Kingdom
}

\begin{abstract}
Lattice structure based morphologically matched scaffolds is rapidly growing facilitated by developments in Additive Manufacturing. These porous structures are particularly promising due to their potential in reducing stress shielding and maladapted stress concentration. Accordingly, this study presents Extra Low Interstitial (ELI) Titanium alloy based morphological scaffolds featuring three different porous architecture. All scaffolds were additively manufactured using Selective Laser Melting from Ti-6Al-4V ELI with porosities of 73.85, 60.53 and $55.26 \%$ with the global geometry dictated through X-Ray Computed Tomography. The elastic and plastic performance of both the scaffold prototypes and the bone section being replaced were evaluated through uniaxial compression testing. Comparing the data, the suitability of the Maxwell criterion in evaluating the stiffness behaviour of fully porous morphological scaffolds are carried out. The outcomes show that the best performing scaffolds presented in this study have high strength $(169 \mathrm{MPa})$ and low stiffness $(5.09 \mathrm{GPa})$ suitable to minimise stress shielding. The matching morphology in addition to high porosity allow adequate space for flow circulation and has the potential to reduce maladapted stress concentration. Finally, the Electron Diffraction X-ray analysis revealed a small difference in the composition of aluminium between the particle and the bonding material at the scaffold surface.
\end{abstract}

Keywords: Morphological Scaffold; Selective Laser Melting; Stress Shielding; Extra Low Interstitial, Additive Manufacturing; Mechanical Performance.

\footnotetext{
${ }^{*}$ Corresponding author. Address: School of Engineering, Faculty of Science and Engineering, University of Wolverhampton, Telford Campus, Shifnal Road, Priorslee, Telford, TF2 9NT, UK. Tel.: +44 (0)1902 321573; fax: +44 (0)1902 323843.

E-mail address: k.bari@wlv.ac.uk (Klaudio Bari).
} 


\section{Introduction}

One of the areas where Additive Manufacturing (AM) is gaining momentum is in the field of biomedical applications, primarily in orthopaedic scaffolds and scaffolds [1-3]. Accordingly, this study centres on the development of porous morphological scaffolds using Selective Laser Melting (SLM) $[4,5]$. Traditionally manufactured bone scaffolds using casting and forging techniques cannot achieve the levels of customisation as possible through AM [6]. Exploiting this capability, this work attempts to morphologically mirror a tibial section while incorporating a fully porous lattice-based design.

In the previous work $[7,8]$, a sheathed scaffold was proposed which on clinical trial incurred a higher risk of infection due to the sheathed architecture; the non-porous designs had the likelihood of being filled with avascular fluid resulting in poor blood supply weakening the immune system. Accordingly, this is the first work that attempts to mimic the bone geometry in addition to stiffness-matching without interrupting the natural loading pattern through the use of porous lattice structures. Furthermore, the possibility of trabecular struts $[9,10]$ in a porous topologically optimised scaffold to fail locally in a single strut or the whole structure due to natural stiffness grading is also analysed.

The work also draws a distinction between imposing a topological optimisation [11] and uniform pore geometry to ensure best fit to their recipients [12]. This is done through direct data input from X-Ray micro-computed tomography $(\mu \mathrm{CT})$ to create a bespoke digital biomodel $[13,14]$. Beyond efficiency, the proposed morphologically matched porous methodology drastically minimises material mass at the same time preserving the bones natural loading pattern in comparison to traditional scaffolds [15].

The scaffold presented considers all the qualifying attributes as suggested by Hutmacher et al. $[16,17]$ such as 'biocompatibility', 'mechanical performance comparable to host bone', 'porosity suitable for ingrowth', 'blood supply, waste transportation and attractive surface morphology for cell attachment and proliferation'. The biocompatibility aspect mainly depends on the materials used and the fabrication process associated. Consequently, the Extra Low Interstitial Titanium alloy (Ti-6Al-4V ELI) used in this study is known to have excellent biocompatibility $[18,19]$. Nevertheless, structures based on Ti alloys are notch sensitive, which demands greater care at the design stage of complex structures to prevent to crack initiation and propagation $[20]$.

Traditional Ti orthopaedic scaffolds have received significant criticism in relation to its higher elastic stiffness (E) in comparison to the cortical bone spectrum of 3 to $30 \mathrm{GPa}$ [21,22] resulting in stress shielding. Even though research efforts [23-28] have focused on the lattice-based reduction of the elastic stiffness of Ti scaffolds, published literature mimicking the mechanical characteristics of the host section without altering the loading pattern are scarce. Dissimilar 
mechanical properties between the scaffold and bone lead to many undesirable effects. One such phenomenon is the maladapted stress concentration due to the differences in elastic modulus or stiffness, leading to bone resorption loosening the scaffold $[29,30]$. A solution to this is to mimic the loading pattern of the segmented bone in addition to using fully porous structures, which have mechanical properties closer to or slightly lower than the bone being replaced.

Another reason to use porous structure is to mimic the structure of native bone is to promote bone ingrowth into the scaffold, which is non-existent when it comes to solid scaffolds $[31,32]$. Furthermore, the surface roughness of scaffolds also play a key role in bone adhesion; a rough surface is often preferred over smooth in this regard [33,34]. Accordingly, AM offers advantages in developing geometrically accurate porous structures that can mimic specific bone geometry which is systematically exploited in this research.

Cellular materials apply the same structural principles of large-scale structures to the mesoscale, creating materials with tailored properties [35-38]. As the density of the lattice material decreases so do its other properties to a certain extent proportionally and then disproportionally. Nevertheless, specific strength and stiffness cannot be increased from that of the base material. In applications where low weight is required but a certain volume or surface is required to be filled, cellular structures are ideal [39]. Exploiting the potential of lattice structures, this paper not only presents an experimental analysis of three innovative lattice designs suitable of delivering substantially lower elastic modulus, but also a road map of building full-scale lattice structure-based multiplication of unit cell (UC).

As the exact requirements of the lattice are dependent on the precise application there was no outright measure of success. Rather the aim was to design a lattice that has elastic modulus lower compared to the bone equally across every surface at the same time mimicking the morphological shape of the bone. Hence the predictability and uniformity of strain and deformation in different lattice topologies are what is primarily being assessed. The primary target was to minimise stress shielding and match the shape of the bone replacement section. Bones are constantly rebuilt and remodelled throughout life in a complex physiological process [40]. The mineralised matrix is formed by cells in the marrow called osteoblasts and resorbed by other cells, osteoclasts. Osteocytes are in contact with other cells on the bone surfaces, and respond to changes in physical forces, maintaining the bone's structure [41-43].

Accordingly, a full porous lattice structure design has been superimposed on the CT scan based digital model to demonstrate the ease of reshaping a simple lattice without disturbing the natural loading pattern. Further to this, experimental compression testing is performed to categorise the best design and to study the failure pattern. Finally, The scaffolds were examined using a scanning electron microscope (SEM) to visualise the surface roughness. The microstructure and 
chemical composition of particle and the bonding material was investigated using Electron Diffraction X-ray (EDX) to quantify the variation in the elemental matrix.

\section{Materials and Methods}

\subsection{Morphology based biomodel}

To obtain an accurate geometry of the tibial section, Laser Coordinate Measuring Machine $(\mathrm{CMM})$ and Multiscale X-ray Computed Tomography $(\mu \mathrm{CT})$ was used [44]. From an adult human tibia specimen, a $2.12 \mathrm{~cm}$ long section representative of a cancerous segment as shown in Fig. 1 was extracted. The section length is purely arbitrary and is representative of cases where autologous bone graft may be considered $[15,45]$. This was considered in order to make sure that scaffold developed can be used for bone growth analysis using bioreactors in the future.

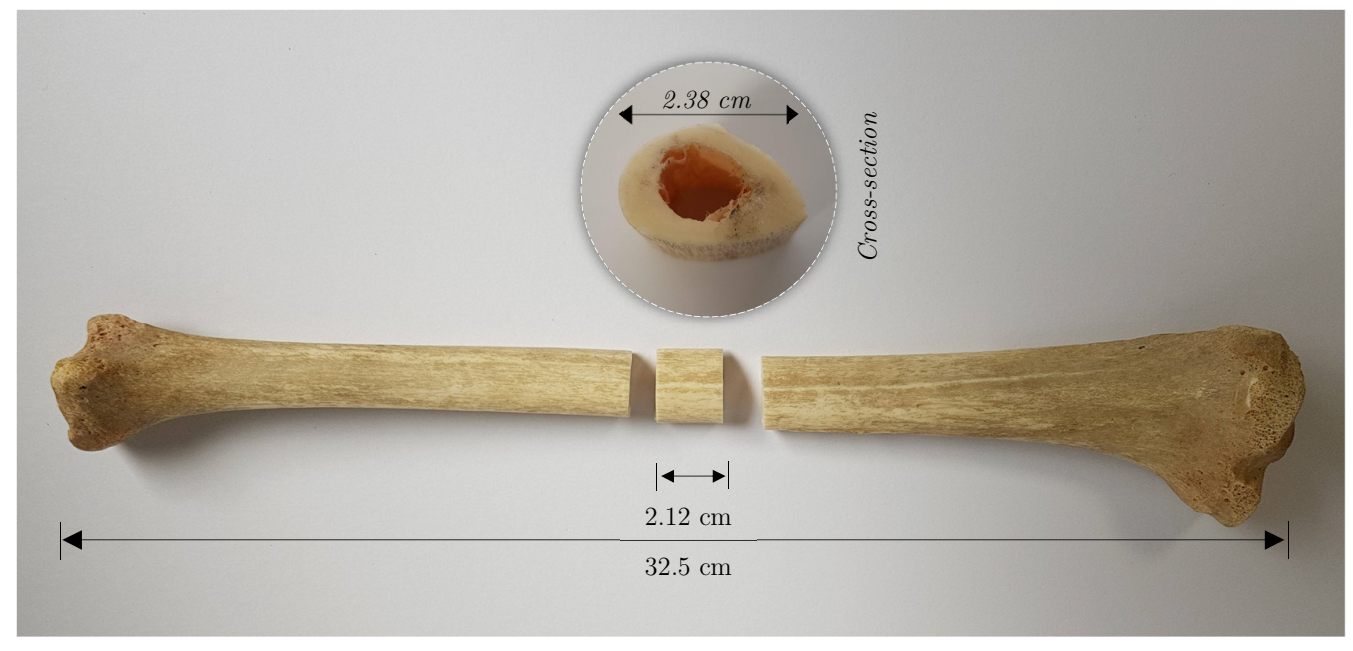

Fig. 1. Global tibia and the section considered for scaffold design.

The bone section was scanned using an industrial CT scanner 2211 made by Bruker and x-ray image of the cross-section was taken rotating the sample from 0 to $360^{\circ}$ at 5 step increments. The cross-sectional images were then stitched together to reconstruct the three-dimensional (3D) morphological data using 'NRecon' (Bruker). The resulting data was found to closely replicate the morphological shape of the sectioned bone. Accordingly, the CT data was filtered and converted into a digital editable model (Parasolid) using 'CT-analyser' to create the biomodel which was used as the foundation for the morphological volume for the scaffold design.

\subsection{Scaffold design}

The primary design requirement was that the scaffold features a significantly lower elastic modulus (E) in comparison to bulk Ti-6Al-4V ELI and performs closer to the stiffness of the tibia section under consideration. This is to avoid weakening of the bone and reducing the service life of both the bone and scaffold due to stress shielding and maladapted stress concentration. According to Yang et al. [46], Young's modulus $\left(\mathrm{E}_{\mathrm{Cort}}\right)$ of cortical bone ranges from 3 to $30 \mathrm{GPa}$ 
and Cancellous bone $\left(\mathrm{E}_{\mathrm{Canc}}\right)$ from 0.02 to $0.5 \mathrm{GPa}$. Consequently, attempts have been made in this work to come up with a morphological lattice structure that behaves within the $\mathrm{E}_{\mathrm{Cort}}$ spectrum. This is to ensure that the working stress is distributed evenly through stiffness matching and bone growth is promoted.

Furthermore, for bone ingrowth requirements, pore size between 50 and $650 \mu \mathrm{m}$ and porosity higher than 50\% [30,31] along with manufacturing constraints (smallest nominal strut thickness of $200 \mu \mathrm{m}$ ) are required. Considering these key requirements, three different unit cell designs UCA, UCB and UCC are conceived as shown in Fig. 2. To satisfy the bone growth requirements, all the three lattices have been designed to have a volumetric porosity $(\varphi)$ greater than $50 \%$, resulting in a measured relative density $\left(\rho_{r_{u c}}\right)$ of $0.36,0.43$ and 0.32 for UCA, UCB and UCC respectively.

The high porosity allows space for bone ingrowth, blood flow and removal of broken bone cells [47]. More importantly, the expectation was to bring the stiffness of Ti-6Al-4V ELI significantly lower to match that of the bone. While the scaffold design was based on the criteria of lattice multiplication, the UC's were designed considering the number of beams $(b)$ and joints $(j)$ to identify the type of dominate stress and to satisfy the Maxwell criterion as shown in Eqn. (1). Where, $M \leq 0$ is bending dominated and $M>0$ is stretch dominated [12].

$$
M=b-3 j+6
$$

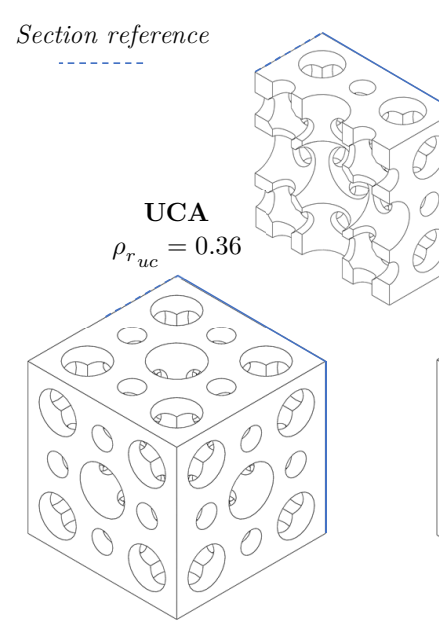

(a)

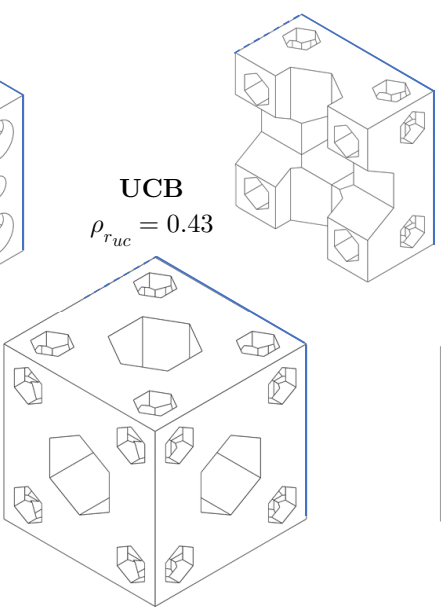

(b)

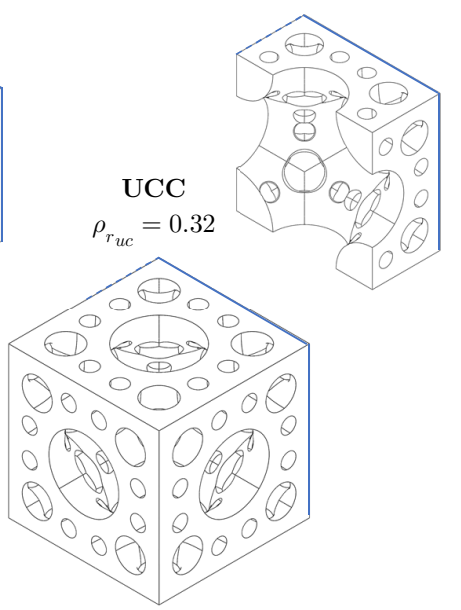

(c)

Fig. 2. Unit cells considered for scaffold designs, where (a) shows the design UCA with a relative density of 0.36 ( $\varphi=63.63 \%)$, (b) shows UCB with a relative density $0.43(\varphi=56.85 \%)$ and (c) shows design UCC with a relative density of and $0.32(\varphi=67.99 \%)$.

All the three UC's were designed to have negative $M$ to cope with the stresses that arise from the elastic strain of walking or running; the upper range in this case is taken as $2500 \mu \varepsilon$ [48] for 
a worst-case scenario. Designing orthopaedic scaffolds using stretch-dominated cellular structures also allow to exploit both the topological advantages and to gain enhanced strength [49].

Using a linear regression algorithm, the scaffold designs mimicking the morphology of the bone was generated. Even though the X-ray $\mu \mathrm{CT}$ created a fine resolution volumetric data of the tibial section, for computational efficiency only the surface topography was extracted for the digital biomodel. This data was then compounded using multipoint splines to generate the topological curvature that mimics the surface morphology of the bone.

A total of three scaffold designs namely SDA, SDB, and SDC featuring unit cells UCA, UCB, and UCC respectively were considered as shown in Fig. 3. As can be seen, all the designs closely mimic the bone morphology at the same time featuring a variety of pore sizes. Overall the highest design porosity was exhibited by SDA at $73.85 \%$ followed by SDC and SDB at $60.53 \%$ and $55.26 \%$ respectively. Accordingly, all three designs comply with the initial condition of $>50 \%$ required for bone growth. Nevertheless, a difference in porosity between the unit cell and scaffold design observed due to the morphological nature of the scaffold design.

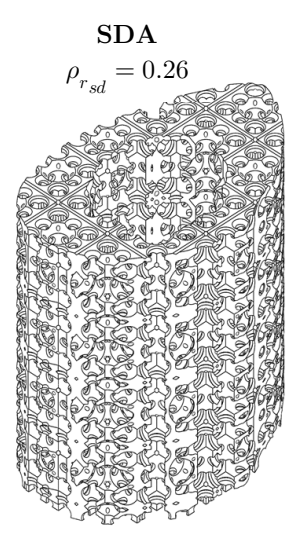

(a)

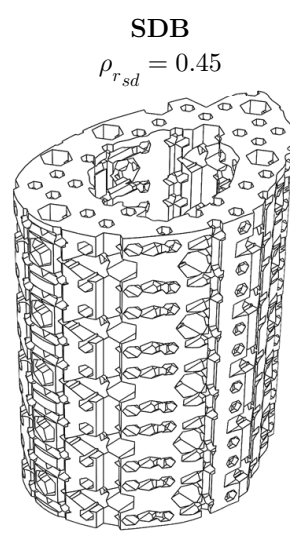

(b)

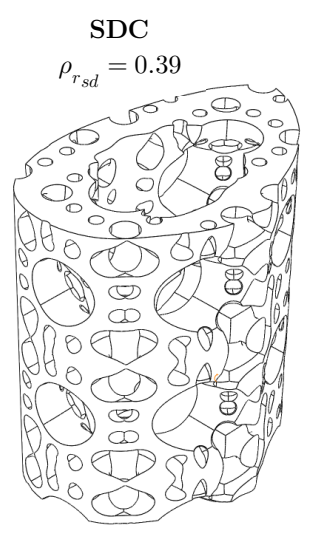

(c)

Fig. 3. Morphological Scaffold designs considered where (a) shows design SDA with a relative density of 0.26 , (b) shows design SDB with a relative density of 0.45 and (c) shows SDC with a relative density of 0.39 .

\subsection{Material selection and manufacturing}

All the three scaffolds were manufactured using the Renishaw healthcare-optimised AM250 (laser spot $60 \mu \mathrm{m}$ ) system using Selective Laser Melting (SLM) at $20 \mu \mathrm{m}$ thick layers. Biocompatible Ti-6Al-4V ELI grade 23 with a density of $4430 \mathrm{Kg} / \mathrm{m}^{3}\left(\rho_{B}\right)$ was the material of choice due to its high strength, low weight ratio and outstanding corrosion resistance. ELI stands for "Extra Low Interstitials" referring to reduced levels of oxygen, nitrogen, carbon and iron as listed in Table 
1. These lower interstitials provide improved ductility and better fracture toughness for Ti-6Al$4 \mathrm{~V}$ material [50,51]. Ti-6Al-4V ELI is inherently stabilised as a mixture of BCC $(\beta)$ and $\mathrm{HCP}$ $(\alpha)$ phases [52-54] with Yield strength ranging 930-795 MPa. While the manufacturers data sheet presented the Young's modulus range between 102 and $118 \mathrm{GPa}$; inhouse tests resulted in modulus of $104.8 \mathrm{GPa}\left(E_{B}\right)$ for the bulk material. Accordingly, for biocompatibility, the materials must be inert in the body 'in vivo'. While surface passivation in general is the primary mechanism by which contamination is prevented, the natural formation of oxide layers by Ti64 ensures sufficient biocompatibility as discussed by Surmeneva et al. [55] and Bandyopadhyay et al. [56].

Table 1. Chemical composition for Ti-6Al-4V ELI used.

\begin{tabular}{cccccccc}
\hline $\mathbf{A l}$ & $\mathbf{V}$ & $\mathbf{C}$ & $\mathbf{F e}$ & $\mathbf{O}$ & $\mathbf{N}$ & $\mathbf{H}$ & $\mathbf{T i}$ \\
\hline $5.5-6.5 \%$ & $3.5-4.5 \%$ & $<0.08 \%$ & $<0.25 \%$ & $<0.13 \%$ & $<0.05 \%$ & $<0.012 \%$ & Balance \\
\hline
\end{tabular}

The AM250 used for SLM belong to a class of powder bed fusion technology [57] as classified by ISO/ASTM 52900:2017 [58] featuring a Gaussian Beam continuous wave fibre laser of $200 \mathrm{~W}$ fitted with a beam splitter mechanism. The laser sintering of the material was conducted through an overhead laser system that modulates based on the process parameters such as laser exposure of $200 \mathrm{~W}$, scan speed of $1200 \mathrm{~mm} / \mathrm{s}$, and a rotated $x$ and $y$ hatching strategy. After the first layer of powder has been processed, the build platform is lowered by one increment and another layer of powder is deposited on to the bed using a recoater at a dosing factor of $140 \%$. The laser then melts the new layer of material fusing it with the previous layer and the process repeats.

The Ti-6Al-4V ELI powder used for the production run was first atomised to obtain a nearly spherical shape within a size range of 10 to $45 \mu \mathrm{m}$. The resulting atomised powder was sieved at $45 \mu \mathrm{m}$ resulting in a near normal particle size distribution with a D50 (50\% particle distribution) of $27 \mu \mathrm{m}$. A range of particle sizes is beneficial for SLM as it increases both the packing density and flowability of the powder, which is significant in obtaining a dense part.

The laser melting was carried out using the contour-hatch strategy, where the 2D layer data from the CAD geometry was used to offset the melt-pool width for high geometrical accuracy. The contours were then traced by the laser followed by the hatch scans to fill the enclosed area. The contour scan diameter was set to match with the laser spot size to ensure further interpolative calculations were not necessary. This technique was found to deliver the most repeatable Ti-6Al-4V ELI parts with a 99.98\% density irrespective of the struct thickness variation between the three unit-cells considered. SLM was conducted in an environment initially vacuumed and then backfilled with $99.995 \%$ pure Argon with an Oxygen content of $\sim 0.1 \%$. The build platform was heated to $35^{\circ} \mathrm{C}$ before the start of sintering and the whole process took 
approximately 6 hours to build nine samples $(3 \times 3)$. Internal supports structures were not possible with the lattices due to the challenges associated with removing them [59]. To overcome this, a self-supporting diagonal build technique with external supports were adopted.

The printed prototypes were sandblasted, and heat treated at $650{ }^{\circ} \mathrm{C}$ for 3 hours under argon environment. While heat treatment does impact the mechanical properties, according to Vrancken et al. [60] its effect on the morphological parameters is negligible. Hence, the effect of heat treatment on the morphological parameters is disregarded. Following heat treatment, the specimens were removed from the $1 \mathrm{~mm}$ build plate support using submerged wire ElectroDischarge Machining (EDM).

\subsection{Experimental Testing}

Compression tests were performed using a Zwick Roell Z1474 materials testing machine having a maximum load capacity of $100 \mathrm{kN}$ as shown in Fig. 4. The physical tests were performed to investigate both the compressive performance of the three different scaffolds and the tibial bone to be replaced. BS EN ISO 7500-1 [61] was referred for the calibration and verification of the test setup. The test samples were loaded to failure through crosshead displacement at a rate of $0.01 \mathrm{~mm} / \mathrm{s}(\partial n / \partial t)$.

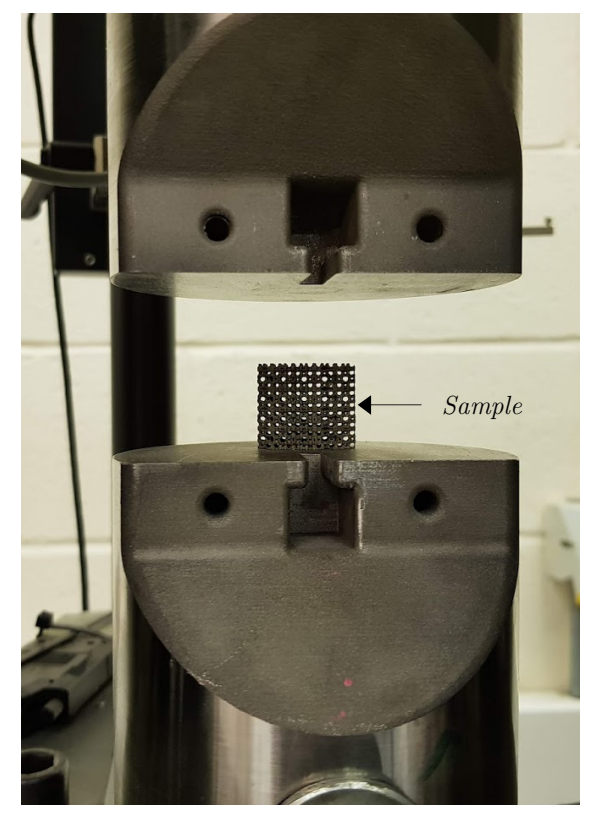

Fig. 4. Compression rig used for the experimental test.

A maximum load of $90 \mathrm{kN}$ with a force shutdown threshold of $50 \%$ and maximum deformation of $4 \mathrm{~mm}$ was applied. A deformation-controlled load was applied to prevent the test from stalling at the elastic limit. Even though for biomedical application, the post-elastic behaviour is of insufficient significance [62], it was necessary to study the failure modes and the overall behaviour 
of the scaffolds. The threshold and deformation values ensured that the compression plates were restrained from colliding. Real-time force-displacement and stress-strain curves were obtained using effective contact surface area and length $21.2 \mathrm{~mm}$. To reduce the error from misalignment, the rig used two photosensor cameras deployed to detect an accurate strain during compression by tracking two illuminated dots that has been attached to the specimen. This eliminated the error due to the interference of machine deflection from jaws and spindle with specimen strain resulting in a higher degree of confidence in the measurement.

\subsection{Chemical composition and microstructure characterisation}

The microstructure and chemical composition of particle and the bonding material was investigated using Electron Backscattered Diffraction (EBSD) and Electron Diffraction X-ray (EDX). Furthermore, the surface roughness of the scaffold resulting from SLM was evaluated using an Olympus LEXT OLS3100 confocal laser scanning microscope.

\section{Results}

\subsection{Biomodel}

The 3D reconstruction of $\mu \mathrm{CT}$ data of the bone section that advised the global geometry of all the three scaffolds is shown in Fig. 5. The data shows the density gradient of the bone in a luminous weighted arbitrary scale from the X-ray absorption $(\alpha)$ data. The biomodel clearly capture the global topography of the bone which allows the scaffold to mimic the topographical morphology. Using the morphological biomodel the infill volume was computed to be $4.24 \times 10^{-6} \mathrm{~m}^{3}\left(V_{\text {Bio }}\right)$ for the bone section under consideration. The topological match allows for enhanced contact area between the scaffold and the host bone. Furthermore, the porosity data is beneficial for functional grading of the scaffolds to allow for enhanced stiffness matching.

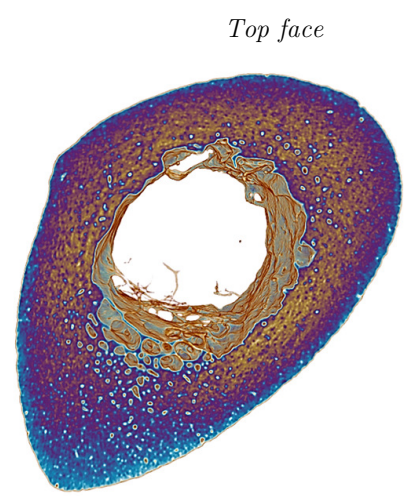

(a)

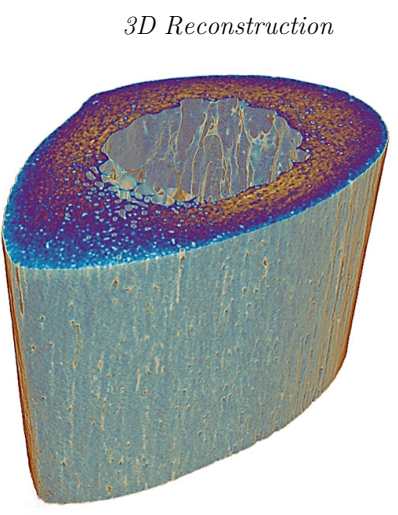

(b)

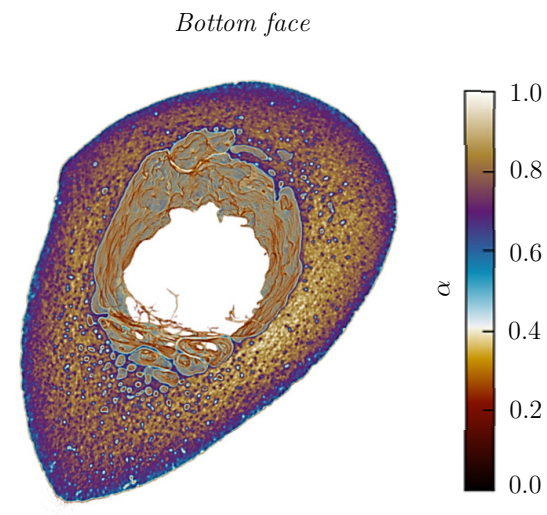

(c)

Fig. 5. Reconstructed $\mu \mathrm{CT}$ data of the tibia section weighted against an arbitrary opacity scale showing relative density based on X-ray absorption $(\alpha)$. 


\subsection{Theoretical characterisation of the unit cell and scaffold design}

Comparing the design features of the unit cell, UCC exhibited the lowest and UCB the highest $\rho_{r_{d}}$ with a maximum difference of $29.3 \%$ as listed in Table 2 . While the relative density was a key variable for porosity, it was also crucial to analyse theoretical stiffness. This was done by evaluating the equivalent Young's modulus $\left(E_{t h r}\right)$ using the Maxwell criterion, the results of which are also presented in Table 2 .

Table 2. Design properties associated with the unit cell and scaffold design.

\begin{tabular}{llllllll}
\hline \multirow{2}{*}{ Property } & \multicolumn{3}{c}{ Unit Cell } & \multicolumn{3}{c}{ Scaffold Design } \\
& UCA & UCB & UCC & SDA & SDB & SDC \\
\hline Density $\left(\rho_{d}\right) \mathrm{Kg} / \mathrm{m}^{3}$ & 1611.37 & 1911.65 & 1417.87 & 1158.65 & 1982.10 & 1748.71 \\
Relative density $\left(\rho_{r_{d}}\right)$ & 0.36 & 0.43 & 0.32 & 0.26 & 0.45 & 0.39 \\
Porosity $(\varphi) \%$ & 63.63 & 56.85 & 67.99 & 73.85 & 55.26 & 60.53 \\
Young's Modulus $\left(E_{t h r}\right)$ Gpa & 13.87 & 19.52 & 10.74 & 7.17 & 20.98 & 16.33 \\
\hline
\end{tabular}

Comparing the results, it can be seen that the theoretical stiffness is primarily influenced by the porosity of the lattice geometry. The highest Young's modulus was exhibited by design UCB which has the lowest porosity and the opposite was true for the design UCC. Comparing this to the scaffold design, the lowest modulus was exhibited by the design SDA featuring the unit cell UCA as opposed to UCC. This is due to the morphological design of the scaffold preventing an asymmetrical distribution of the material. Accordingly, when it comes to the theoretical performance of the scaffold, SDA showed the lowest stiffness followed by SDC. Nevertheless, the elastic performance of all the scaffold designs was within the cortical bone spectrum of 3 to 30 GPa.

\subsection{Additive manufacture and compressive behaviour}

The additively manufactured scaffolds using Ti-6Al-4V ELI is shown in Fig. 6. After visual inspection, X-ray $\mu \mathrm{CT}$ scan of the prototypes was carried out to ascertain the internal quality. The cross-sectional slices were stitched together, and an arbitrary colour contour based on Xray absorption was applied to show the density gradation (Fig. 7). On the arbitrary scale, the lowest colour grading represents fully porous and highest represents fully dense.

As expected with SLM, a rough surface finish was created due to the stair-step effect that occurs during manufacturing represented as a porous outer layer in Fig. 7. All cellular structures showed interconnected porosity, which is one of the key factors for tissue ingrowth. The average strut thickness of lattices varied between $100 \mu \mathrm{m}$ (SFA) and $900 \mu \mathrm{m}$ (SDC).

Mechanical performance of the scaffold designs following the uniaxial compression tests are presented in Table 3. The representative stress-strain curves for the three scaffold designs are 
shown in Fig. 8. Based on the experimental test data, the highest Young's modulus $\left(E_{\text {exp }}\right)$ was exhibited by SDB followed by SDC and SDA at 6.07, 5.42 and 5.09 GPa respectively. This trend was expected as SDA featured the lowest relative density of 0.26 , followed by SDC and SDB at 0.39 and 0.45 respectively. A similar trend was observed when it comes to bearing strength $\left(\sigma_{y_{\text {exp }}}\right)$, where SDA showed the lowest performance at $169 \mathrm{MPa}$ and SDB the highest at 343 MPa. This shows that the micro-architecture and the selection of unit cell has a significant impact on the bearing strength due to the morphological boundary requirements.

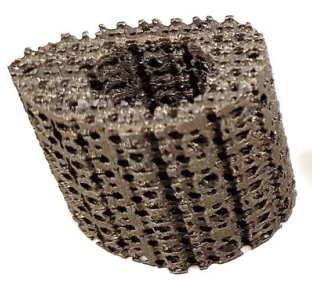

SDA

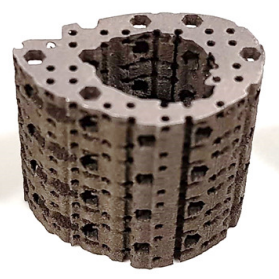

SDB

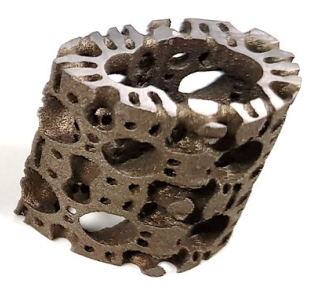

SDC

Fig. 6. Additively manufactured Ti-6Al-4V ELI scaffolds.

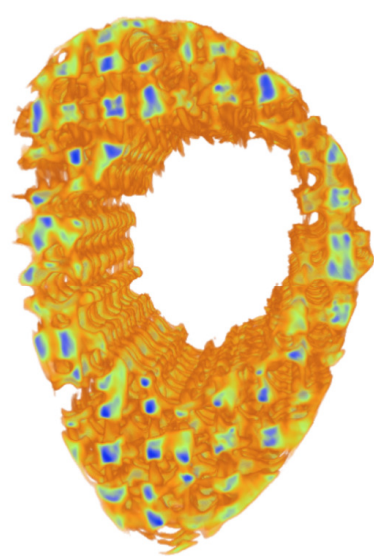

SDA

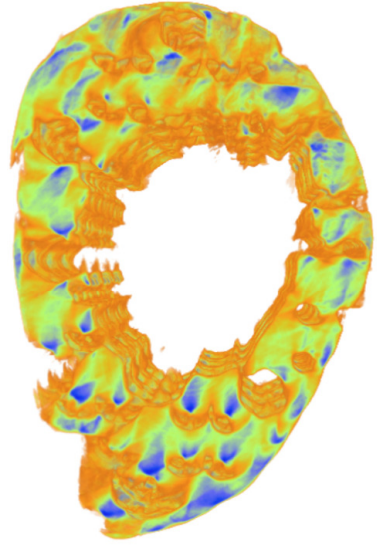

SDB

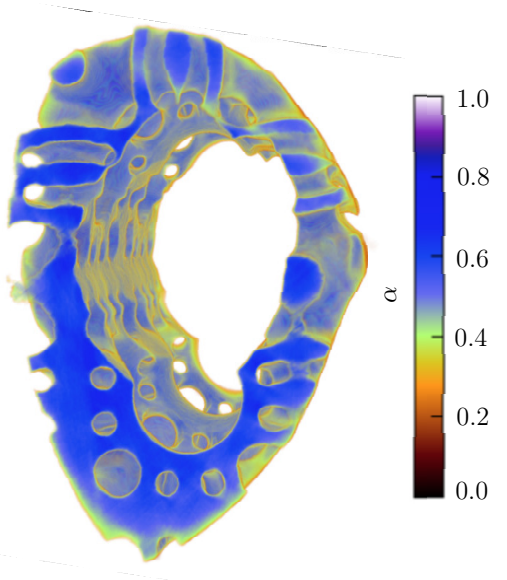

SDC

Fig. 7. Reconstructed $\mu \mathrm{CT}$ data of the sheathed scaffold weighted against an arbitrary opacity scale showing microporosity based on X-ray absorption $(\alpha)$.

Comparison of these values indicates that all the scaffold designs have mechanical properties lower than the bone being replaced. From the stress-strain curve, three characteristic regions can be separated: elastic deformation region (up to the first peak value in the strain-stress curve); plateau region (region of almost constant stress); and a densification region(rapid increase in stress). In elastic regime under uniaxial stress (close to linear initial parts of the strain-stress curves) open-cell scaffolds deform primarily by bending of the struts. 


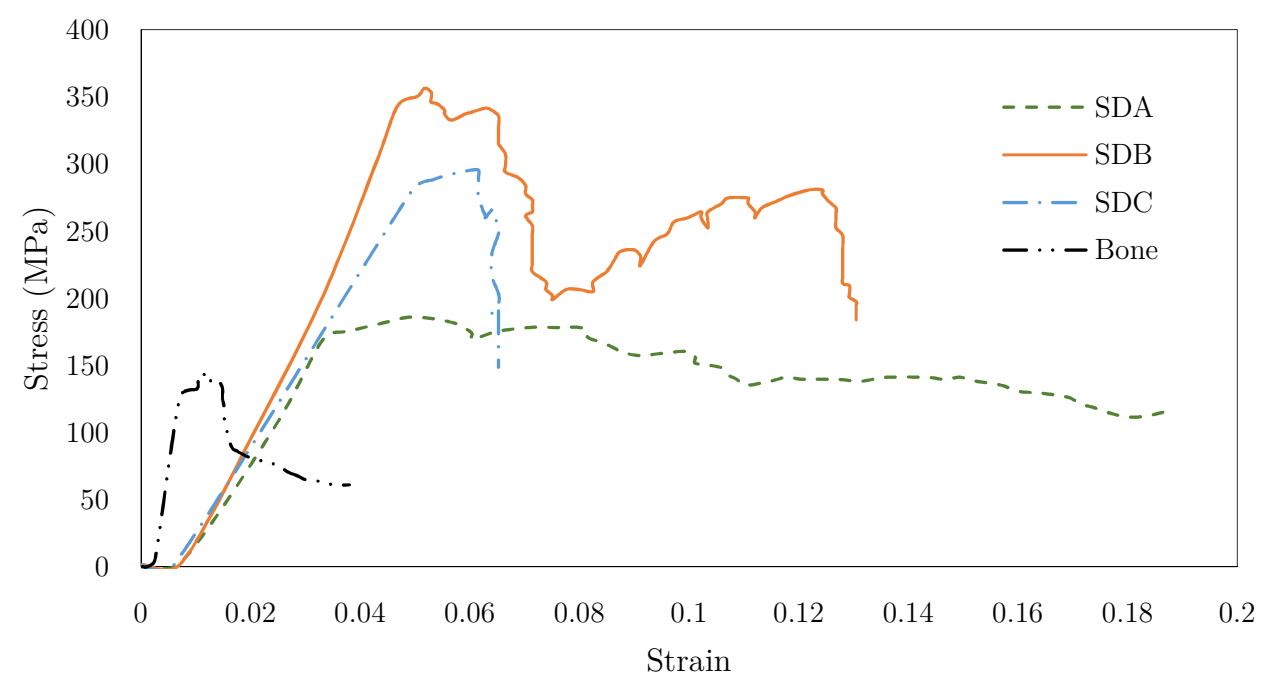

Fig. 8. Experimental stress-strain curve for the scaffold designs in comparison with bone.

Table 3. Mechanical performance of the scaffold designs.

\begin{tabular}{lllll}
\hline Property & SDA & SDB & SDC & Bone \\
\hline Young's Modulus $\left(E_{\text {exp }}\right)$ GPa & 5.09 & 6.07 & 5.42 & 18.01 \\
Bearing strength $\left(\sigma_{y_{\text {exp }}}\right) \mathrm{MPa}$ & 169 & 343 & 280 & 140 \\
\hline
\end{tabular}

The region of the stress-strain curve plateau of the scaffold types SDB and SDC is serrated. While stress fluctuation in the plateau region is a typical characteristic of brittle cellular materials [63] lattices with low relative densities $(\sim 10-20 \%)$ can be deformed up to relatively large strains $(\sim 70-80 \%)$ before densification occurs [64]. Accordingly, the abrupt drop in stress for SDC is caused by the total mesh collapse following densification. It is clear that the morphology of the lattice structures influences the scaffold deformation character in a very pronounced way.

Fig. 9 presents selected still frames from the video recorded during the uniaxial compression. Chosen frames correspond to the initial (almost not compressed) state; the moment of the first failure at $25 \%, 75 \%$, and $100 \%$ plastic deformation. The SDA design that features small circular pores is mainly fracturing through the formation of crush bands (Fig. 9a). Moreover, these bands propagate along the directions different from the loading one.

SDA also showed barrel-shaped bulging, that can be attributed to the increased lateral resistance. On the initial assessment of the failed sample shown in Fig. 9b, failure patterns resembling thin wall buckling are visible. However, failure occurred per lattice layer where two complete layers were deformed one after the other clearly captured in the stress-strain curve. The failure of SDC was abrupt with a sudden reduction in the load carrying capacity of 
approximately $50 \%$, this is expected to be due to the localised stress concentration of thin sharp sections. However, the failure is representative of a brittle classification.

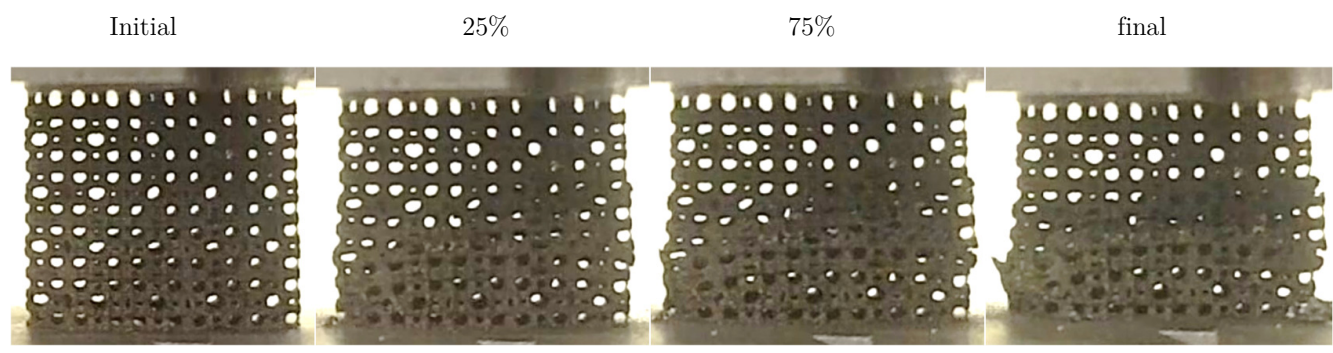

(a)

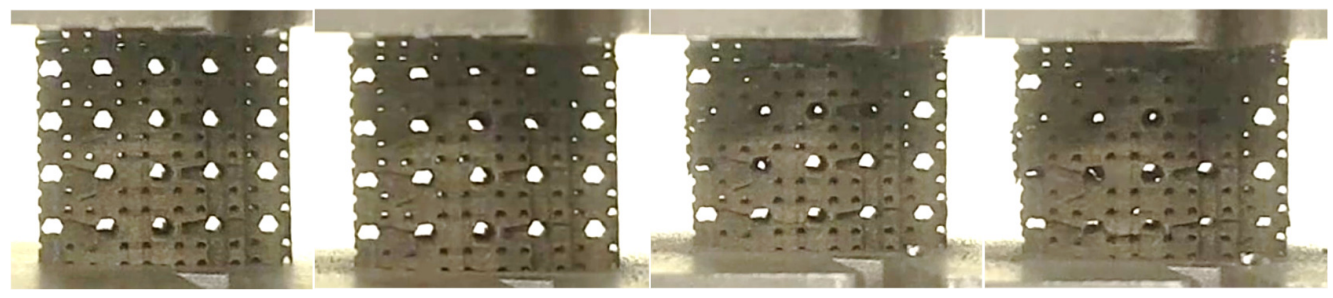

(b)

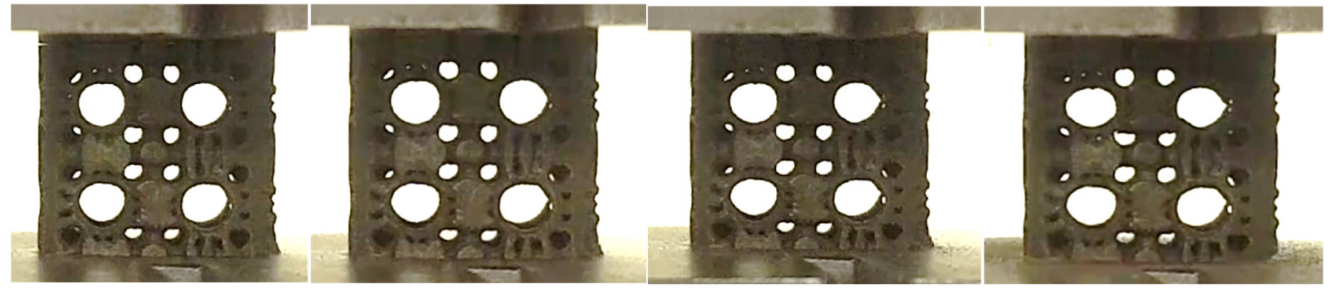

(c)

Fig. 9. Compressive deformation of the scaffold showing failure for (a) SDA, (b) SDB and (c) SDC.

\subsection{Chemical composition and microstructure}

The scaffolds were examined using a scanning electron microscope (SEM) to visualise the surface roughness of the top and sides as shown in Fig. 10. The top view shown in Fig. 10a show open pores that can provide perfect incubation of the osteoblast on the surface [65]. It is a known fact that rougher surfaces allow the bone cells to grip into the scaffold pores [66]. The side view of the surface in Fig. 10b shows the surface edge of the scaffold at $100 \mu \mathrm{m}$ scale.

The interconnectivity has multiple pores ranging from 96 to 125um. As suggested by Faeda et al. [67] varying degrees of surface roughness can enhance bone adhesion and growth. From a manufacturing viewpoint, at scales of both 30 and $100 \mu \mathrm{m}$, the surface appears to have no clear consistency or smooth edges as featured in the idealised CAD model. This is clearly a characteristic of the laser melting manufacturing process which, in this scenario, acts as a benefit to the design. Furthermore, semi-molten Ti-6Al-4V ELI particles were observed as shown in Fig. 11. 


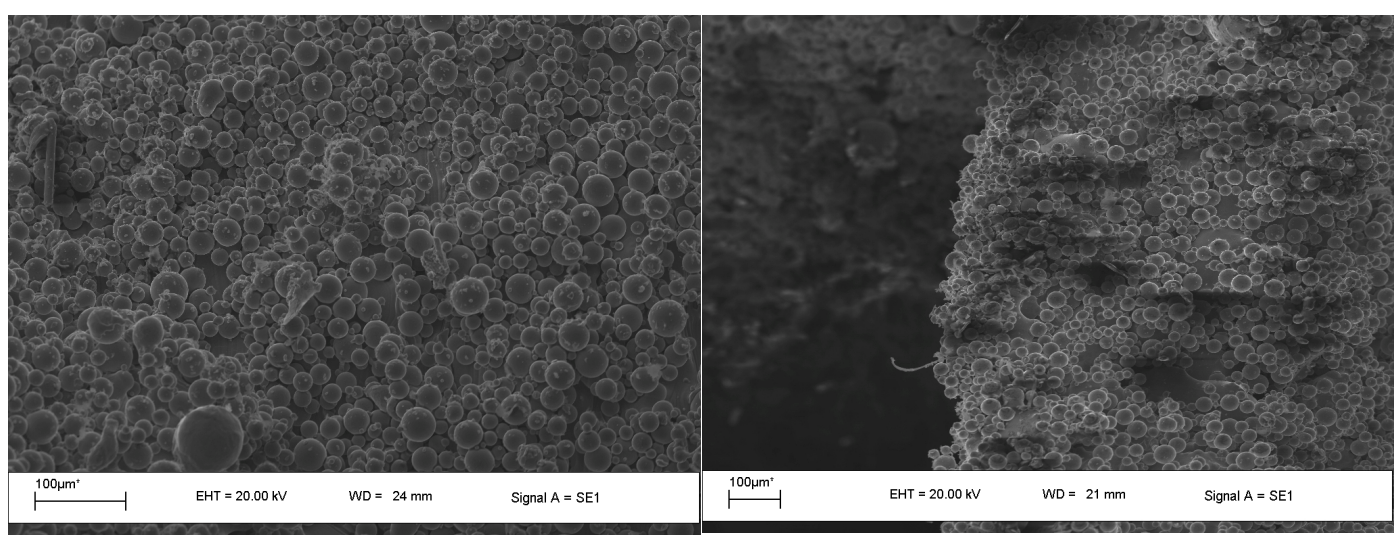

(a)

(b)

Fig. 10. SEM images of the scaffold surface (a) top view and (b) side view.

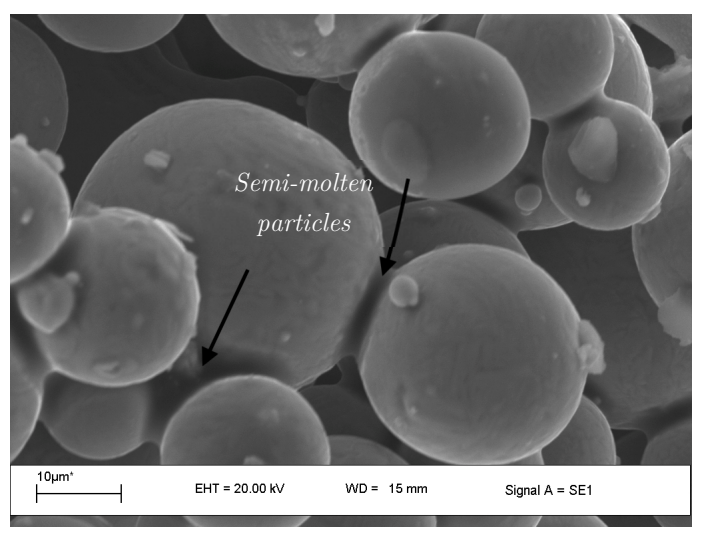

Fig. 11. SEM image of the surface that shows the semi-molten Ti-6Al-4V ELI particle.

The microstructure and chemical composition of particle and the bonding material was investigated using Electron Diffraction X-ray (EDX). The resulting elemental composition is listed in Table 4. There is a clear difference in the elemental composition (Al wt\%) between the particle and the bonding material. This shows the requirement of further optimisation of the laser melting and heat treatment process parameter to ensure the redistribution of $\mathrm{Al}$ evenly across the surface. Nevertheless, this change has been observed on the surface only and there is no indication of any elemental composition or phase change of $\mathrm{Al}$ in the melted pool.

Table 4. Elemental composition of the particle and bounded area obtained from EDX.

\begin{tabular}{lllll}
\hline Spectrum & Al & Ti & V & Total \\
\hline Bonding & 0.93 & 93.88 & 5.19 & 100 \\
Particle & 6.59 & 89.75 & 3.65 & 100 \\
Melted pool & 6.00 & 90.02 & 4.00 & 100 \\
Std. deviation & 0.08 & 0.12 & 0.06 & - \\
Max. & 6.19 & 90.88 & 4.11 & - \\
Min. & 5.91 & 89.75 & 3.85 & - \\
\hline
\end{tabular}




\section{Discussion}

The use of porous scaffolds as bone substitutes for large segmental bone defect is hindered by the limited vascularisation, bone ingrowth, stress shielding and maladapted stress concentration $[15,40,55,68]$. In a previous study, the possibility of anatomical scaffolds featuring a sheathed design was proposed for possible stiffness matching and to mimic the structure of the bone [7]. However, it was found that a sheathed design was unfeasible due to limited vascularisation and the risk of infection due to avascular fluid build-up. In addition, tubular stents proposed in several earlier studies altered the natural loading pattern of the bone anatomical mismatch [6971]. Accordingly, it is evident that stress shielding, osseointegration, and maladapted stress concentration are still a challenging problem for bone scaffolds.

In the study, three different porous scaffolds that mimics the global morphology of the bone being replaced is investigated. From Fig. 5, it is evident that the biomodel effectively capture the morphology of the bone allowing to preserve the natural stiffness grading along with an unaltered loading pattern. This is particularly important when it comes to maladapted stress concentration, an area which is widely unconsidered in many studies.

The advancement in X-ray $\mu \mathrm{CT}$ scan and digital design prompted the research question whether a porous lattice could be combined with morphological grading for potential stiffness matching. Fig. 6 shows that the approach was successful as the scaffold closely resembles the profile of the bone being replaced allowing for enhanced contact area at the scaffold interface. However, morphing an ideal unit cell into the biomodel may not be the ideal approach as Fig. 7 shows open edges and thin sections as a result of the unsymmetrical cross-section. Nevertheless, the CT-scan data of the scaffolds shows uniform density with minimal variation across the solid struts. An added advantage was the significant porosity across the scaffold surface as a result of the selective laser melting manufacturing considered. The Maxwell criterion was used to predict the mechanical properties of the lattice structure as a design guideline. This was an important consideration, as the relative density of the unit cells further changed when morphed into the morphological volume.

As listed in Table 2, the relative density of all the unit cells changed when morphed into the biomodel. The highest difference was exhibited when UCA was morphed into SDA

$\left(U C A \stackrel{\rho_{r_{d}}}{\Rightarrow} S D A\right)$ where $\rho_{r_{d}}$ changed from 0.36 to 0.26 , a difference of $32 \%$. The lowest variation was for $U C B \stackrel{\rho_{r_{d}}}{\Rightarrow} S D B$ at $5 \%$ followed by $U C C \stackrel{\rho_{r_{d}}}{\Rightarrow} S D C$ at $20 \%$. This means that the theoretical performance of the unit cell predicted using Maxwell criteria is not an indication of the performance that can be exhibited from the final scaffold design. The resultant difference in the theoretical Young's modulus followed a similar trend with the highest and lowest variation for $\mathrm{UCA}$ and UCB respectively. 
The stiffness of bone depends on age and location within the body. Accordingly, the cortical bone's modulus (E) falls within the spectrum of 3 to $30 \mathrm{GPa}$. In this study, the compression test on the segmented bone properties resulted in an experimental E value of 18.01 (Table 3) GPa. Accordingly, Young's modulus of all the scaffold designs falls within the cortical bone spectrum for potential stiffness matching. However, the theoretical modulus at the design stage is speculated using the Maxwell criteria which is a function of the relative density and bulk material property alone. Consequently, the morphological influence on mechanical performance is not considered at the design stage.

Significant efforts in literature are evident from Sing et al. [72-74], Calignano [75] and du Plessis et al. [76] on developing optimum process parameters for emerging Titanium-based alloys and bioprinting. Despite the ambiguity around the influence of part orientation and SLM process parameters [77], the lattice designs and dimensions considered in this study are within the optimal manufacturing range for SLM process considered in Ti-6Al-4V ELI. In most cases, a variation in mechanical performance is a result of the difference in density, porosity or microstructure. The X-Ray CT scan of the SLM manufactured scaffolds featuring the threelattice design shown in Fig. 7 demonstrates no density variation as a result of the SLM process. Furthermore, the laser spot and weld pool thickness associated with the SLM process are considerably small with respect to the lattice dimensions considered resulting in a highly dense (99.98\%) part in all the three cases. In addition, the EDX analysis showed no variation in $\beta$ phases or microstructure between the designs considered.

From the experimental stress-strain curve shown in Fig. 8, it is clear that $E_{\text {exp }}$ between the scaffold are comparable despite the large difference in $\rho_{r_{d}}$. Comparing the elastic performance as shown in Table 3, the lowest stiffness was exhibited by SDA followed by SDC and SDB at a difference of $6 \%$ (SDA vs SDC) and $11 \%$ (SDC vs SDB) respectively. Comparing the experimental performance to the theoretical prediction, the closest performance was found for SDA at 5.09 GPa and 7.17 GPa respectively (32\% difference) however, for the other designs the difference was significant. The results show that the Maxwell criteria significantly overestimates the $\mathrm{E}$ values due to its assumption on the asymmetric distribution of material within the lattice. This means that the irregular morphological nature of the geometry and the non-uniform lattice geometry cannot be approximated using this technique. Furthermore, the Maxwell criterion is purely based on relative density and assumes that the material is distributed evenly within the global structure. When comparing the performance, the worst agreement between the two methods was observed at the highest relative density.

Young's modulus of traditionally manufactured metallic scaffolds using Ti-6Al-4V are much higher at $114 \mathrm{GPa}$ [12] and $104.8 \mathrm{GPa}\left(E_{B}\right)$ for ELI [78]. Thus, morphological scaffolds developed in this study revealed significantly decreased E values compared with fully dense alloys. This 
leads to the reduction of stress-shielding and maladapted stress concentration between the scaffold and bone. In addition to a lower stiffness, the scaffold needs to be strong enough in terms of bearing strength to transfer the mechanical load without large deformation. The cortical and cancellous bones have bearing strengths of 100-230 MPa and 2-12 MPa respectively [79].

The experimental test carried out on the bone being replaced resulted in a bearing strength of approximately $140 \mathrm{MPa}$, which falls within the traditionally classified spectrum. In comparison, all scaffold designs performed above the bone section as shown in Fig. 8 and summarised in Table 3. Overall, SDA showed the most comparable performance at a difference of $18 \%$ followed by SDC and SDB. However, it can be noted that despite the very close Young's modulus between the three scaffold designs, the bearing strength increased by 1.65 and 2 folds when SDA was compared to SDC and SDB respectively. This is due to the overall porosity (wt\%) and the nonuniform pore sizes featured in these designs.

Even though all the designs exhibited lower stiffness properties and higher bearing strength than the bone being replaced, SDA is the most suitable as it satisfies also the bone growth requirement. Previous studies on optimising lattice designs show that cell penetration, bone ingrowth, vascularisation, and nutrient delivery is primarily dependent on pore size $[47,80,81]$. Even though the exact pore size for bone ingrowth still remains controversial, it has been shown that pore size 100 and $900 \mu \mathrm{m}$ are highly effective in enabling bone ingrowth $[82,83]$.

From the stress-strain curve, three characteristic regions can be separated as shown in Fig. 8 . The region of the stress-strain curve plateau of SDB is slightly serrated which is a typical characteristic associated with brittle cellular materials [84]. The reason for this seems to be the hexagonal pore shape. The finding can be related to the observations of Heinl et al. [85] and Kadkhodapour et al. [5] who used Electron Beam Melting (EBM) to manufacture regular porous structures featuring diamond unit cell. In their work, the diamond structure with a porosity of 81.1\% exhibited significant serration and brittle like failure. Accordingly, it can be concluded that shapes such as diamond or hexagon featuring sharp corners with high porosity can lead to brittle behaviour in additively manufactured Ti-6Al-4V. Furthermore, for highly porous geometries, the pore shape primarily dictates the occurrence of stress serration. This observation can be related to Gorny et al. [86] and Merk et al. [87] where a brittle failure of Ti64 lattice structures under quasi-static compression was reported.

For SDC, the abrupt drop in compressive stress is due to the total collapse of the wall section. Therefore, it is clear that the morphology of the overall structure in addition to the lattice shape must be considered in unison at the design stage of morphological scaffolds. The stress before the onset of strong plastic deformation for the scaffold type SDB is the highest primarily because of the lower porosity (55.26 wt\%). However, no region of constant stress can be observed for neither SDB or SDC. For SDA, the stress in the plateau regime is almost horizontal showing 
that the failure is slow and controlled by the layer deformation. In addition, SDA also satisfies the pore size requirement for effective bone growth. Accordingly, SDA can be considered the best scaffold design in terms of both stress behaviour, stiffness and bone ingrowth requirement.

Fig. 9 shows that SDA is fracturing through the formation of crush bands experiencing bulging with sections splitting in radial direction typical of ductile failure. The 4-layer lattice SDB showed a complete failure of first and last layers as represented by the two peaks. The failure was representative of thin-walled failure as a result of the anatomical profile. The failure was also influenced by the uneven distribution of material when the unit cell was morphed into the morphological profile. SDC showed catastrophic failure due to localised stress concentration. Bearing strength and ductility of a scaffold critical to prevent a catastrophic failure that can occur in the event of an accidental overload or localised strain. However, they typically demand conflicting and even opposing approaches when it comes to materials and design. However, the results of SDA show that morphological cellular structures from Ti-6Al-4V ELI can provide a unique combination of high bearing strength and ductility.

Fig. 10 shows loosely bonded and partially melted particles at the surfaces of the scaffold. Due to the powder bed fusion considered for the laser melting, granules from the surrounding powder bed are always present in the lattice structures $[88,89]$. This allows the creation of controlled rougher surfaces by controlling the particle size and shape of the powder bed. For bone scaffolds, rougher surfaces are often preferred for the bone cells to grip into the scaffold pores. It was found that the scaffolds presented have interconnected surface porosity ranging from 96 to $125 \mathrm{\mu m}$. Furthermore, semi-molten Ti-6Al-4V ELI particles were also observed as shown in Fig. 11. As the titanium alloys feature vanadium and aluminium (despite the small quantity), the scaffold may have toxic effects as a result of leaching from the semi-molten particles [90]. Consequently, this aspect of the research needs further investigation to quantify the associated risk factor.

Pore diameter and throat size play an important role in the effectiveness (rate) of bone ingrowth [91,92]. According to Yang et al. [93] and Zhang et al. [94], pore size and interconnectivity are key factors in optimising the flow of nutrients and waste, leading to better osseointegration. Warnke et al. [82] after studying Ti alloys from pore size ranging from 450 to $1200 \mu \mathrm{m}$ found that there was thorough occlusion at $450 \mu \mathrm{m}$, and occlusion decreased with increase in pore sizes. No occlusion was observed in the samples that featured pore sizes between 900 and $1200 \mu \mathrm{m}$. Compare this to the performance of the scaffold presented in this study, SDA satisfies the requirement to prevent occlusion. Furthermore, the interconnected porosity throughout the scaffold means that the flow of nutrients and waste are not obstructed make it suitable for effective osteointegration. Furthermore, bone cells are anchorage-dependent [95] and it has been shown that for traditional porous scaffolds bone ingrowth is skewed at the corners. Accordingly, graded lattice structures are often recommended to preserve the natural loading pattern of the 
bone $[96,97]$. Accordingly, the morphological scaffold proposed in this paper is superior in this aspect as it simulates a natural loading pattern.

The EDX analysis (Table 4) revealed a difference in the $\mathrm{Al}$ composition between the particle and the bonding material. This shows the requirement of further optimisation of the laser melting and heat treatment process parameter to ensure the redistribution of $\mathrm{Al}$ evenly across the surface. This change has been observed on the surface only and there is no indication of any elemental composition or phase change of $\mathrm{Al} w \mathrm{t} \%$ in the melted pool.

This work has investigated the compressive behaviour of laser melted Ti-6Al-4V ELI scaffolds by using an alternative morphological matched design methodology. From the results, the SDA has been proposed as the optimal design configuration. It is thought that this morphologically matched scaffold could potentially be utilised for segmental bone repair. This work has highlighted the use of SLM to produce more flexible and lightweight Ti-6Al-4V ELI scaffolds that could potentially assist in reducing stress shielding and therefore contribute to improving the longevity of bone repair scaffolds. Although further study is needed to optimise the design and stress distribution, the geometry and mechanical properties presented demonstrates the feasibility of porous morphological scaffolds. Consequently, the most important contributions of the current study are presenting a novel and unique fully porous design for the development of multi-layered metallic scaffolds that offers non-serrated (ductile) behaviour.

\section{Conclusion}

The study developed a unique multi-layered fully porous scaffold that mimics the morphology of the bone being replaced. The compressive behaviour of the scaffolds was investigated through uniaxial testing of prototypes manufactured using SLM and compared to the performance of the bone section being replaced. The results show that Extra Low Interstitial Ti-6Al-4V scaffolds featuring porosities of 55.26-73.85\% exhibited bearing strength and Young's modulus of 169-343 MPa and 5.09-6.07 GPa respectively. A performance significantly closer to the bone section that measured a bearing strength of $140 \mathrm{MPa}$ and modulus of $18.01 \mathrm{GPa}$. Despite the morphological match, the study confirms that the design of the lattice cell determines the failure mechanism. The best scaffold prototype SDA deliver high strength (169 MPa) and low stiffness (5.09 GPa) in addition to the morphologically graded stiffness that can reduce stress shielding and maladapted stress concentration. Furthermore, the $73.85 \%$ porosity and $\sim 900-1000 \mu \mathrm{m}$ pore diameter meet the requirement for bone ingrowth. The design is fully porous and

has clear passages and available space for blood circulation, and waste removal. The porous scaffold SDA together with bioactive and carrier materials for controlled drug 
release has the potential to become a bone graft substitute providing an improvement to the existing state of the art scaffolds.

\section{Data availability}

The data that support the findings of this study are available from the corresponding author upon reasonable request.

\section{References}

[1] C.K. Chua, K.F. Leong, 3D Printing and additive manufacturing: Principles and applications (with companion media pack) - fourth edition of rapid prototyping, 2014. doi:10.1142/9008.

[2] D. Bak, Rapid prototyping or rapid production? 3D printing processes move industry towards the latter, Assem. Autom. 23 (2003) 340-345. doi:10.1108/01445150310501190.

[3] B. Derby, Printing and prototyping of tissues and scaffolds, Science (80-. ). 338 (2012) 921-926. doi:10.1126/science.1226340.

[4] S.M. Ahmadi, G. Campoli, S. Amin Yavari, B. Sajadi, R. Wauthle, J. Schrooten, H. Weinans, A.A. Zadpoor, Mechanical behavior of regular open-cell porous biomaterials made of diamond lattice unit cells, J. Mech. Behav. Biomed. Mater. 34 (2014) 106-115. doi:10.1016/j.jmbbm.2014.02.003.

[5] J. Kadkhodapour, H. Montazerian, A. Darabi, A.P. Anaraki, S.M. Ahmadi, A.A. Zadpoor, S. Schmauder, Failure mechanisms of additively manufactured porous biomaterials: Effects of porosity and type of unit cell, J. Mech. Behav. Biomed. Mater. 50 (2015) 180-191. doi:10.1016/j.jmbbm.2015.06.012.

[6] J. Banhart, Manufacture, characterisation and application of cellular metals and metal foams, Prog. Mater. Sci. 46 (2001) 559-632. doi:10.1016/S0079-6425(00)00002-5.

[7] A. Vance, K. Bari, A. Arjunan, Compressive performance of an arbitrary stiffness matched anatomical Ti64 implant manufactured using Direct Metal Laser Sintering, 160 (2018) 1281-1294.

https://www.sciencedirect.com/science/article/pii/S0264127518308128 (accessed December 27, 2018).

[8] A. Vance, K. Bari, A. Arjunan, Investigation of Ti64 sheathed cellular anatomical structure as a tibia implant, Biomed. Phys. Eng. Express. 5 (2019) 035008. doi:10.1088/2057-1976/ab0bd7.

[9] Y. Torres, P. Trueba, J.J. Pavón, E. Chicardi, P. Kamm, F. García-Moreno, J.A. Rodríguez-Ortiz, Design, processing and characterization of titanium with radial graded porosity for bone implants, Mater. Des. 110 (2016) 179-187. doi:10.1016/j.matdes.2016.07.135.

[10] L.J. Gibson, Biomechanics of cellular solids, J. Biomech. 38 (2005) 377-399. doi:10.1016/j.jbiomech.2004.09.027.

[11] S.M. Giannitelli, D. Accoto, M. Trombetta, A. Rainer, Current trends in the design of scaffolds for computer-aided tissue engineering, Acta Biomater. 10 (2014) 580-594. doi:10.1016/j.actbio.2013.10.024.

[12] X.P. Tan, Y.J. Tan, C.S.L. Chow, S.B. Tor, W.Y. Yeong, Metallic powder-bed based 3D printing of cellular scaffolds for orthopaedic implants: A state-of-the-art review on manufacturing, topological design, mechanical properties and biocompatibility, Mater. Sci. Eng. C. 76 (2017) 1328-1343. doi:10.1016/j.msec.2017.02.094.

[13] W.G. Shadid, A. Willis, Bone fragment segmentation from 3D CT imagery, Comput. Med. Imaging Graph. 66 (2018) 14-27. doi:10.1016/j.compmedimag.2018.02.001.

[14] S. Barui, S. Chatterjee, S. Mandal, A. Kumar, B. Basu, Microstructure and compression properties of 3D powder printed Ti-6Al-4V scaffolds with designed porosity: Experimental and computational analysis, 
Mater. Sci. Eng. C. 70 (2017) 812-823. doi:10.1016/j.msec.2016.09.040.

[15] R. Chung, D.M. Kalyon, X. Yu, A. Valdevit, Segmental bone replacement via patient-specific, threedimensional printed bioresorbable graft substitutes and their use as templates for the culture of mesenchymal stem cells under mechanical stimulation at various frequencies, Biotechnol. Bioeng. (2018). doi:10.1002/bit.26780.

[16] D.W.D.W. Hutmacher, Scaffolds in tissue engineering bone and cartilage, Biomaterials. 21 (2000) 25292543. doi:10.1016/S0142-9612(00)00121-6.

[17] J.C. Reichert, M.E. Wullschleger, A. Cipitria, J. Lienau, T.K. Cheng, M.A. Schütz, G.N. Duda, U. Nöth, J. Eulert, D.W. Hutmacher, Custom-made composite scaffolds for segmental defect repair in long bones, Int. Orthop. 35 (2011) 1229-1236. doi:10.1007/s00264-010-1146-x.

[18] A.T. Sidambe, Biocompatibility of Advanced Manufactured Titanium Implants-A Review., Mater. (Basel, Switzerland). 7 (2014) 8168-8188. doi:10.3390/ma7128168.

[19] M. Niinomi, Biologically and Mechanically Biocompatible Titanium Alloys, (n.d.). doi:10.2320/matertrans.L-MRA2008828.

[20] I.D. Learmonth, C. Young, C. Rorabeck, The operation of the century: total hip replacement, Lancet. 370 (2007) 1508-1519. doi:10.1016/S0140-6736(07)60457-7.

[21] K. Tai, M. Dao, S. Suresh, A. Palazoglu, C. Ortiz, Nanoscale heterogeneity promotes energy dissipation in bone, Nat. Mater. 6 (2007) 454-462. doi:10.1038/nmat1911.

[22] E. Novitskaya, P.-Y. Chen, E. Hamed, J. Li, V.A. Lubarda, I. Jasiuk, J. McKittrick, Recent advances on the measurement and calculation of the elastic moduli of cortical and trabecular bone: a review, 2011. http://www.doiserbia.nb.rs/img/doi/1450-5584/2011/1450-55841103209N.pdf (accessed January 21, 2019).

[23] M. Khodaei, A. Valanezhad, I. Watanabe, R. Yousefi, Surface and mechanical properties of modified porous titanium scaffold, Surf. Coatings Technol. 315 (2017) 61-66. doi:10.1016/j.surfcoat.2017.02.032.

[24] B. Song, X. Zhao, S. Li, C. Han, Q. Wei, S. Wen, J. Liu, Y. Shi, Differences in microstructure and properties between selective laser melting and traditional manufacturing for fabrication of metal parts: A review, Front. Mech. Eng. 10 (2015) 111-125. doi:10.1007/s11465-015-0341-2.

[25] Y. Chen, J.E. Frith, A. Dehghan-Manshadi, H. Attar, D. Kent, N.D.M. Soro, M.J. Bermingham, M.S. Dargusch, Mechanical properties and biocompatibility of porous titanium scaffolds for bone tissue engineering, J. Mech. Behav. Biomed. Mater. 75 (2017) 169-174. doi:10.1016/j.jmbbm.2017.07.015.

[26] L. Yan, J. Wu, L. Zhang, X. Liu, K. Zhou, B. Su, Pore structures and mechanical properties of porous titanium scaffolds by bidirectional freeze casting, Mater. Sci. Eng. C. 75 (2017) 335-340. doi:10.1016/j.msec.2016.12.044.

[27] C. Wang, H. Chen, X. Zhu, Z. Xiao, K. Zhang, X. Zhang, An improved polymeric sponge replication method for biomedical porous titanium scaffolds, Mater. Sci. Eng. C. 70 (2017) 1192-1199. doi:10.1016/j.msec.2016.03.037.

[28] L. Zhao, X. Pei, L. Jiang, C. Hu, J. Sun, F. Xing, C. Zhou, Y. Fan, X. Zhang, Bionic design and 3D printing of porous titanium alloy scaffolds for bone tissue repair, Compos. Part B Eng. 162 (2019) 154-161. doi:10.1016/j.compositesb.2018.10.094.

[29] G. Ryan, A. Pandit, D.P. Apatsidis, Fabrication methods of porous metals for use in orthopaedic applications, Biomaterials. 27 (2006) 2651-2670. doi:10.1016/j.biomaterials.2005.12.002.

[30] O.L.A.O.L.A. Harrysson, O. Cansizoglu, D.J.D.J. Marcellin-Little, D.R.D.R. Cormier, H.A. West, H.A. West II, Direct metal fabrication of titanium implants with tailored materials and mechanical properties using electron beam melting technology, Mater. Sci. Eng. C. 28 (2008) 366-373. 
doi:10.1016/j.msec.2007.04.022.

[31] S. Ponader, C. Von Wilmowsky, M. Widenmayer, R. Lutz, P. Heinl, C. Körner, R.F. Singer, E. Nkenke, F.W. Neukam, K.A. Schlegel, In vivo performance of selective electron beam-melted Ti-6Al-4V structures, J. Biomed. Mater. Res. - Part A. 92 (2010) 56-62. doi:10.1002/jbm.a.32337.

[32] A. Palmquist, A. Snis, L. Emanuelsson, M. Browne, P. Thomsen, Long-term biocompatibility and osseointegration of electron beam melted, free-form-fabricated solid and porous titanium alloy: Experimental studies in sheep, J. Biomater. Appl. 27 (2013) 1003-1016. doi:10.1177/0885328211431857.

[33] M. De Wild, R. Schumacher, K. Mayer, E. Schkommodau, D. Thoma, M. Bredell, A. Kruse Gujer, K.W. Grätz, F.E. Weber, Bone regeneration by the osteoconductivity of porous titanium implants manufactured by selective laser melting: A histological and micro computed tomography study in the rabbit, Tissue Eng. Part A. 19 (2013) 2645-2654. doi:10.1089/ten.tea.2012.0753.

[34] G. Zhao, A.L. Raines, M. Wieland, Z. Schwartz, B.D. Boyan, Requirement for both micron- and submicron scale structure for synergistic responses of osteoblasts to substrate surface energy and topography, Biomaterials. 28 (2007) 2821-2829. doi:10.1016/j.biomaterials.2007.02.024.

[35] L. Piaia, G.V. Salmoria, D. Hotza, Additive manufacturing of nanostructured bone scaffolds, in: Nanostructured Biomater. Cranio-Maxillofacial Oral Appl., Elsevier, 2018: pp. 181-210. doi:10.1016/B978-012-814621-7.00010-X.

[36] C.F. Marques, S.M. Olhero, P.M.C. Torres, J.C.C. Abrantes, S. Fateixa, H.I.S. Nogueira, I.A.C. Ribeiro, A. Bettencourt, A. Sousa, P.L. Granja, J.M.F. Ferreira, Novel sintering-free scaffolds obtained by additive manufacturing for concurrent bone regeneration and drug delivery: Proof of concept, Mater. Sci. Eng. C. 94 (2019) 426-436. doi:10.1016/j.msec.2018.09.050.

[37] A. Arjunan, Acoustic Absorption of Passive Destructive Interference Cavities, Mater. Today Commun. (2018). doi:10.1016/j.mtcomm.2018.12.012.

[38] A. Arjunan, Targeted sound attenuation capacity of 3D printed noise cancelling waveguides, Appl. Acoust. 151 (2019) 30-44. doi:10.1016/J.APACOUST.2019.03.008.

[39] V.S. Deshpande, M.F. Ashby, N.A. Fleck, Foam topology: Bending versus stretching dominated architectures, Acta Mater. 49 (2001) 1035-1040. doi:10.1016/S1359-6454(00)00379-7.

[40] F. Eckstein, M. Hudelmaier, R. Putz, The effects of exercise on human articular cartilage, J. Anat. 208 (2006) 491-512. doi:10.1111/j.1469-7580.2006.00546.x.

[41] H. Kagami, H. Agata, R. Kato, F. Matsuoka, A. Tojo, Fundamental Technological Developments Required for Increased Availability of Tissue Engineering, in: Regen. Med. Tissue Eng. - Cells Biomater., InTech, 2011. doi: $10.5772 / 21137$.

[42] M. Baghaban, F. Faghihi, Mesenchymal Stem Cell-Based Bone Engineering for Bone Regeneration, in: Regen. Med. Tissue Eng. - Cells Biomater., InTech, 2011. doi:10.5772/21017.

[43] D. Eberli, Regenerative Medicine and Tissue Engineering - Cells and Biomaterials, InTech, 2011. doi: $10.5772 / 837$.

[44] P.J. Withers, X-ray nanotomography, Mater. Today. 10 (2007) 26-34. doi:10.1016/S1369-7021(07)70305-X.

[45] J.P. SCHMiTZ, J.O. HOLLINGER, The Critical Size Defect as an Experimental Model for Craniomandibulofacial Nonunions, Clin. Orthop. Relat. Res. NA; (1986) 299???308. doi:10.1097/00003086198604000-00036.

[46] S. Zhao, S.J. Li, W.T. Hou, Y.L. Hao, R. Yang, R.D.K. Misra, The influence of cell morphology on the compressive fatigue behavior of Ti-6Al-4V meshes fabricated by electron beam melting, J. Mech. Behav. Biomed. Mater. 59 (2016) 251-264. doi:10.1016/j.jmbbm.2016.01.034. 
[47] N. Taniguchi, S. Fujibayashi, M. Takemoto, K. Sasaki, B. Otsuki, T. Nakamura, T. Matsushita, T. Kokubo, S. Matsuda, Effect of pore size on bone ingrowth into porous titanium implants fabricated by additive manufacturing: An in vivo experiment, Mater. Sci. Eng. C. 59 (2016) 690-701.

doi:10.1016/j.msec.2015.10.069.

[48] C. Milgrom, A. Finestone, Y. Levi, A. Simkin, I. Ekenman, S. Mendelson, M. Millgram, M. Nyska, N. Benjuya, D. Burr, Do high impact exercises produce higher tibial strains than running?, Br. J. Sports Med. 34 (2000) 195-9. doi:10.1136/BJSM.34.3.195.

[49] J. Bauer, S. Hengsbach, I. Tesari, R. Schwaiger, O. Kraft, High-strength cellular ceramic composites with 3D microarchitecture, Proc. Natl. Acad. Sci. U. S. A. 111 (2014) 2453-2458. doi:10.1073/pnas.1315147111.

[50] M. Bisht, N. Ray, F. Verbist, S. Coeck, Correlation of selective laser melting-melt pool events with the tensile properties of Ti-6Al-4V ELI processed by laser powder bed fusion, Addit. Manuf. 22 (2018) 302-306. doi:10.1016/J.ADDMA.2018.05.004.

[51] Y. Zhai, H. Galarraga, D.A. Lados, Microstructure, static properties, and fatigue crack growth mechanisms in Ti-6Al-4V fabricated by additive manufacturing: LENS and EBM, Eng. Fail. Anal. 69 (2016) 3-14. doi:10.1016/j.engfailanal.2016.05.036.

[52] N. Velisavljevic, G.N. Chesnut, Direct hcp $\rightarrow$ bcc structural phase transition observed in titanium alloy at high pressure, Appl. Phys. Lett. 91 (2007) 101906. doi:10.1063/1.2780078.

[53] A.R. McAndrew, M. Alvarez Rosales, P.A. Colegrove, J.R. Hönnige, A. Ho, R. Fayolle, K. Eyitayo, I. Stan, P. Sukrongpang, A. Crochemore, Z. Pinter, Interpass rolling of Ti-6Al-4V wire + arc additively manufactured features for microstructural refinement, Addit. Manuf. 21 (2018) 340-349. doi:10.1016/J.ADDMA.2018.03.006.

[54] A. Pesach, E. Tiferet, S.C. Vogel, M. Chonin, A. Diskin, L. Zilberman, O. Rivin, O. Yeheskel, E.N. Caspi, Texture analysis of additively manufactured Ti-6Al-4V using neutron diffraction, Addit. Manuf. 23 (2018) 394-401. doi:10.1016/J.ADDMA.2018.08.010.

[55] M.A. Surmeneva, R.A. Surmenev, E.A. Chudinova, A. Koptioug, M.S. Tkachev, S.N. Gorodzha, L.-E. Rännar, Fabrication of multiple-layered gradient cellular metal scaffold via electron beam melting for segmental bone reconstruction, Mater. Des. 133 (2017) 195-204. doi:10.1016/J.MATDES.2017.07.059.

[56] A. Bandyopadhyay, F. Espana, V.K. Balla, S. Bose, Y. Ohgami, N.M. Davies, Influence of porosity on mechanical properties and in vivo response of Ti6Al4V implants, Acta Biomater. 6 (2010) 1640-1648. doi:10.1016/j.actbio.2009.11.011.

[57] J.M. Lee, S.L. Sing, M. Zhou, W.Y. Yeong, 3D bioprinting processes: A perspective on classification and terminology, Int. J. Bioprinting. 4 (2018). doi:10.18063/ijb.v4i2.151.

[58] ISO/ASTM 52900:2017, Additive manufacturing - General principles — Terminology (ISO/ASTM 52900:2017), BSI Stand. Publ. (2017).

[59] L.D. Bobbio, S. Qin, A. Dunbar, P. Michaleris, A.M. Beese, Characterization of the strength of support structures used in powder bed fusion additive manufacturing of Ti-6Al-4V, Addit. Manuf. 14 (2017) 60-68. doi:10.1016/J.ADDMA.2017.01.002.

[60] R. Wauthle, B. Vrancken, B. Beynaerts, K. Jorissen, J. Schrooten, J.-P.J.-P. Kruth, J. Van Humbeeck, Effects of build orientation and heat treatment on the microstructure and mechanical properties of selective laser melted Ti6Al4V lattice structures, Addit. Manuf. 5 (2015) 77-84. doi:10.1016/j.addma.2014.12.008.

[61] ISO 7500-1:2018 - Metallic materials -- Calibration and verification of static uniaxial testing machines -Part 1: Tension/compression testing machines -- Calibration and verification of the force-measuring system, 2018. https://www.iso.org/standard/72572.html (accessed January 28, 2019).

[62] K.B. Hazlehurst, C.J. Wang, M. Stanford, An investigation into the flexural characteristics of functionally 
graded cobalt chrome femoral stems manufactured using selective laser melting, Mater. Des. 60 (2014) 177183. doi:10.1016/j.matdes.2014.03.068.

[63] X.Y. Cheng, S.J. Li, L.E. Murr, Z.B. Zhang, Y.L. Hao, R. Yang, F. Medina, R.B. Wicker, Compression deformation behavior of Ti-6Al-4V alloy with cellular structures fabricated by electron beam melting, J. Mech. Behav. Biomed. Mater. 16 (2012) 153-162. doi:10.1016/j.jmbbm.2012.10.005.

[64] S.J. Li, Q.S. Xu, Z. Wang, W.T. Hou, Y.L. Hao, R. Yang, L.E. Murr, Influence of cell shape on mechanical properties of Ti-6Al-4V meshes fabricated by electron beam melting method, Acta Biomater. 10 (2014) 4537-4547. doi:10.1016/j.actbio.2014.06.010.

[65] L. Marinucci, S. Balloni, E. Becchetti, S. Belcastro, M. Guerra, M. Calvitti, C. Lilli, E.M. Calvi, P. Locci, Effect of titanium surface roughness on human osteoblast proliferation and gene expression in vitro., Int. J. Oral Maxillofac. Implants. 21 (n.d.) 719-25. http://www.ncbi.nlm.nih.gov/pubmed/17066632 (accessed January 29, 2019).

[66] D. Yamashita, M. Machigashira, M. Miyamoto, H. Takeuchi, K. Noguchi, Y. Izumi, S. Ban, Effect of surface roughness on initial responses of osteoblast-like cells on two types of zirconia., Dent. Mater. J. 28 (2009) 461-70. http://www.ncbi.nlm.nih.gov/pubmed/19721284 (accessed January 29, 2019).

[67] R.S. Faeda, H.S. Tavares, R. Sartori, A.C. Guastaldi, E. Marcantonio, Evaluation of titanium implants with surface modification by laser beam. Biomechanical study in rabbit tibias., Braz. Oral Res. 23 (n.d.) 137-43. http://www.ncbi.nlm.nih.gov/pubmed/19684947 (accessed January 29, 2019).

[68] C. Ding, G. Jones, A.E. Wluka, F. Cicuttini, What can we learn about osteoarthritis by studying a healthy person against a person with early onset of disease?, Curr. Opin. Rheumatol. 22 (2010) 520-527. doi:10.1097/BOR.0b013e32833b90e9.

[69] A. Das, E. Botchwey, Evaluation of angiogenesis and osteogenesis, Tissue Eng. - Part B Rev. 17 (2011) 403-414. doi:10.1089/ten.teb.2011.0190.

[70] Y.-F. Feng, L. Wang, X. Li, Z.-S. Ma, Y. Zhang, Z.-Y. Zhang, W. Lei, Influence of Architecture of $\beta$ Tricalcium Phosphate Scaffolds on Biological Performance in Repairing Segmental Bone Defects, PLoS One. 7 (2012). doi:10.1371/journal.pone.0049955.

[71] C. Gérard, C.J. Doillon, Facilitating tissue infiltration and angiogenesis in a tubular collagen scaffold, J. Biomed. Mater. Res. - Part A. 93 (2010) 615-624. doi:10.1002/jbm.a.32568.

[72] S.L. Sing, S. Wang, S. Agarwala, F.E. Wiria, T.M.H. Ha, W.Y. Yeong, Fabrication of titanium based biphasic scaffold using selective laser melting and collagen immersion, Int. J. Bioprinting. 3 (2017). doi:10.18063/IJB.2017.01.007.

[73] S.L. Sing, F.E. Wiria, W.Y. Yeong, Selective laser melting of lattice structures: A statistical approach to manufacturability and mechanical behavior, Robot. Comput. Integr. Manuf. 49 (2018) 170-180. doi:10.1016/J.RCIM.2017.06.006.

[74] S.L. Sing, F.E. Wiria, W.Y. Yeong, Selective laser melting of titanium alloy with 50 wt\% tantalum: Effect of laser process parameters on part quality, Int. J. Refract. Met. Hard Mater. 77 (2018) 120-127. doi:10.1016/j.ijrmhm.2018.08.006.

[75] F. Calignano, Investigation of the accuracy and roughness in the laser powder bed fusion process, Virtual Phys. Prototyp. 13 (2018) 97-104. doi:10.1080/17452759.2018.1426368.

[76] A. du Plessis, I. Yadroitsava, I. Yadroitsev, S. le Roux, D. Blaine, Numerical comparison of lattice unit cell designs for medical implants by additive manufacturing, Virtual Phys. Prototyp. 13 (2018) 266-281. doi:10.1080/17452759.2018.1491713.

[77] D. Agius, K.I. Kourousis, C. Wallbrink, D. Agius, K.I. Kourousis, C. Wallbrink, A Review of the As-Built SLM Ti-6Al-4V Mechanical Properties towards Achieving Fatigue Resistant Designs, Metals (Basel). 8 
(2018) 75. doi:10.3390/met8010075.

[78] J.H. Shaikh, N.K. Jain, V.C. Venkatesh, Precision Finishing of Bevel Gears by Electrochemical Honing, Mater. Manuf. Process. 28 (2013) 1117-1123. doi:10.1080/10426914.2013.811737.

[79] X. Wang, S. Xu, S. Zhou, W. Xu, M. Leary, P. Choong, M. Qian, M. Brandt, Y.M.Y.M. Xie, Topological design and additive manufacturing of porous metals for bone scaffolds and orthopaedic implants: A review, Biomaterials. 83 (2016) 127-141. doi:10.1016/j.biomaterials.2016.01.012.

[80] P. Heinl, L. Müller, C. Körner, R.F. Singer, F.A. Müller, Cellular Ti-6Al-4V structures with interconnected macro porosity for bone implants fabricated by selective electron beam melting, Acta Biomater. 4 (2008) 1536-1544. doi:10.1016/j.actbio.2008.03.013.

[81] K.F. Leong, C.K. Chua, N. Sudarmadji, W.Y. Yeong, Engineering functionally graded tissue engineering scaffolds, J. Mech. Behav. Biomed. Mater. 1 (2008) 140-152. doi:10.1016/j.jmbbm.2007.11.002.

[82] P.H. Warnke, T. Douglas, P. Wollny, E. Sherry, M. Steiner, S. Galonska, S.T. Becker, I.N. Springer, J. Wiltfang, S. Sivananthan, Rapid Prototyping: Porous Titanium Alloy Scaffolds Produced by Selective Laser Melting for Bone Tissue Engineering, Tissue Eng. Part C Methods. 15 (2009) 115-124. doi:10.1089/ten.tec.2008.0288.

[83] G. Hannink, J.J.C. Arts, Bioresorbability, porosity and mechanical strength of bone substitutes: What is optimal for bone regeneration?, Injury. 42 (2011) S22-S25. doi:10.1016/J.INJURY.2011.06.008.

[84] T.H. Courtney, Mechanical behavior of materials, McGraw Hill, 2000.

[85] P. Heinl, C. Körner, R.F. Singer, Selective electron beam melting of cellular titanium: Mechanical properties, Adv. Eng. Mater. 10 (2008) 882-888. doi:10.1002/adem.200800137.

[86] B. Gorny, T. Niendorf, J. Lackmann, M. Thoene, T. Troester, H.J. Maier, In situ characterization of the deformation and failure behavior of non-stochastic porous structures processed by selective laser melting, 528 (2011) 7962-7967. https://www.sciencedirect.com/science/article/pii/S0921509311008057 (accessed January 30, 2019).

[87] S. Merkt, C. Hinke, J. Bültmann, M. Brandt, Y.M. Xie, Mechanical response of TiAl6V4 lattice structures manufactured by selective laser melting in quasistatic and dynamic compression tests, J. Laser Appl. 27 (2015). doi:10.2351/1.4898835.

[88] X. Tan, Y. Kok, W.Q. Toh, Y.J. Tan, M. Descoins, D. Mangelinck, S.B. Tor, K.F. Leong, C.K. Chua, Revealing martensitic transformation and $\alpha / \beta$ interface evolution in electron beam melting threedimensional-printed Ti-6Al-4V, Sci. Rep. 6 (2016). doi:10.1038/srep26039.

[89] A.A. Antonysamy, J. Meyer, P.B. Prangnell, Effect of build geometry on the $\beta$-grain structure and texture in additive manufacture of Ti6Al4V by selective electron beam melting, Mater. Charact. 84 (2013) 153-168. doi:10.1016/j.matchar.2013.07.012.

[90] G.H. Frydman, R.P. Marini, V. Bakthavatchalu, K.E. Biddle, S. Muthupalani, C.R. Vanderburg, B. Lai, P.K. Bendapudi, R.G. Tompkins, J.G. Fox, Comparative Medicine Local and Systemic Changes Associated with Long-term, Percutaneous, Static Implantation of Titanium Alloys in Rhesus Macaques (Macaca mulatta), 2017.

https://www.ingentaconnect.com/contentone/aalas/cm/2017/00000067/00000002/art00010?crawler=true (accessed March 11, 2019).

[91] V. KARAGEORGIOU, D. KAPLAN, Porosity of 3D biomaterial scaffolds and osteogenesis, Biomaterials. 26 (2005) 5474-5491. doi:10.1016/j.biomaterials.2005.02.002.

[92] B. Otsuki, M. Takemoto, S. Fujibayashi, M. Neo, T. Kokubo, T. Nakamura, Pore throat size and connectivity determine bone and tissue ingrowth into porous implants: Three-dimensional micro-CT based structural analyses of porous bioactive titanium implants, Biomaterials. 27 (2006) 5892-5900. 
doi:10.1016/j.biomaterials.2006.08.013.

[93] S. Yang, K.-F. Leong, Z. Du, C.-K. Chua, The design of scaffolds for use in tissue engineering. Part II. Rapid prototyping techniques, Tissue Eng. 8 (2002) 1-11. doi:10.1089/107632702753503009.

[94] Z. Zhang, D. Jones, S. Yue, P.D. Lee, J.R. Jones, C.J. Sutcliffe, E. Jones, Hierarchical tailoring of strut architecture to control permeability of additive manufactured titanium implants., Mater. Sci. Eng. C. Mater. Biol. Appl. 33 (2013) 4055-62. doi:10.1016/j.msec.2013.05.050.

[95] R.K. Sinha, F. Morris, S.A. Shah, R.S. Tuan, Surface composition of orthopaedic implant metals regulates cell attachment, spreading, and cytoskeletal organization of primary human osteoblasts in vitro., Clin. Orthop. Relat. Res. (1994) 258-72. http://www.ncbi.nlm.nih.gov/pubmed/8050238 (accessed January 30, 2019).

[96] M. Rumpler, A. Woesz, J.W.C. Dunlop, J.T. van Dongen, P. Fratzl, The effect of geometry on threedimensional tissue growth., J. R. Soc. Interface. 5 (2008) 1173-80. doi:10.1098/rsif.2008.0064.

[97] S. Van Bael, Y.C. Chai, S. Truscello, M. Moesen, G. Kerckhofs, H. Van Oosterwyck, J.-P. Kruth, J. Schrooten, The effect of pore geometry on the in vitro biological behavior of human periosteum-derived cells seeded on selective laser-melted Ti6Al4V bone scaffolds, Acta Biomater. 8 (2012) 2824-2834.

doi:10.1016/J.ACTBIO.2012.04.001. 